IP Periodica Polytechnica Civil Engineering

62(1), pp. 80-91, 2018

https://doi.org/10.3311/PPci.9893

Creative Commons Attribution (i)

RESEARCH ARTICLE

\section{Seismic Failure Modes and Deformation Capacity of Reinforced Concrete Columns under Cyclic Loads}

\author{
Ma Ying ${ }^{1,2 *}$, Gong Jin-xin ${ }^{2}$
}

Received 15 August 2016; Revised 18 March 2017; Accepted 12 May 2017

\begin{abstract}
This paper investigates the seismic failure modes and horizontal deformation capacity of reinforced concrete square columns based on the pseudo-static test. The controlled variables include shear aspect ratio, axial load ratio and stirrup spacing. The seismic failure modes, the inelastic deformation capacity after yielding and the deformation components due to flexure, shear and anchorage slip of the RC columns were analyzed, especially flexural-shear failure. The results show that decreasing shear aspect ratio, or increasing axial load or stirrup spacing can result in the change of column failure mode from flexural failure to flexural-shear failure or shear failure, the pinching of hysteresis loops, the reductions of hysteresis loop area and deformation capacity. With the increase of total displacement, all three displacement components increased; the contribution of flexure displacement in total displacement reduced, the contribution of shear displacement increased, the contribution of anchorage slip displacement changed in the range of $30 \%-40 \%$.
\end{abstract}

\section{Keywords}

reinforced concrete, rectangular column, cyclic loads, seismic failure modes, deformation capacity, displacement components

\section{Instruction}

Reinforced concrete (RC) columns are one of the most critical load-bearing components in building structures, highway bridges and subsurface structures. Recent post-earthquake investigations indicate that a large number of bridge piers and structure columns with insufficient and poor seismic details are prone to shear failure, which may result in the overall collapse of bridges and structures under strong seismic attack [1-4]. Studies of engineering practice demonstrate that RC columns under axial force, shear force and bending moment, usually exhibit three failure modes: flexural failure, shear failure and flexural- shear failure [5, 6].

Recently, considerable efforts have been made to investigate the seismic performance of RC columns, such as Lehman etc. [7], Xiao and Zhang [8], Si etc. [9]. The previous researches have primarily focused on the mechanism of flexural failure, and the fibre model can be used to simulate the flexural characteristic of columns. Brittle shear failure, which occurs before flexural yielding of the longitudinal reinforcement, can be easily identified for RC columns. However, the study of flexuralshear failure ("shear failure after yielding") is still inadequate due to flexure shear interaction. Lynn etc. [10] carried out reversed cyclic loading tests on eight full-scale RC columns, and found that predominant failure modes included flexuralshear failure, shear failure, lap-splice failure, and gravity load collapse, increasing axial load or longitudinal reinforcement ratio could lead to shear failure and lower ductility. Xiao and Martirossyan [11] found that the RC columns with insufficient confining reinforcement ratios could be dominated by flexural-shear failure in the plastic-hinge zones. Sezen [12] tested four full-scale lightly RC building columns to investigate the behaviour of columns with significant stiffness and strength degradation due to shear failure after the flexural strength (i.e. flexural-shear failure), and observed that under the same flexural demand and very high axial load, the specimen had a sudden shear and axial load failure. Si etc. [13] conducted quasi-static tests to study the seismic flexural-shear damage mechanisms and rapid repair techniques for earthquake damaged bridge piers. The failure pattern, strength, ductility and 
dissipated energy parameters and stiffness degradation of the repaired specimens were compared with the original ones.

In addition, little studies were carried out on the displacement components of RC columns. Lehman and Moehle [14] tested five well-confined concrete bridge columns and considered that the lateral displacement of columns included three components: flexural displacement, shear displacement, and reinforcement slip displacement, which were measured and calculated. Sezen [12] did the similar study and found the maximum shear displacement was up to $40 \%$ of total displacement. $\mathrm{Li}$ [15] also measured the displacement components and indicated that the flexural displacement had the greatest contributions, which was above 50\%, and the shear displacement was only around $10 \%$. Cai etc. [16] conducted cyclic loading tests of six short columns, separated the shearing and bending responses and analyzed both variations during loading.

In this paper, $24 \mathrm{RC}$ columns were designed with different shear aspects, axial loads and transverse steel ratios, and tested under combined constant axial load and reversed horizontal load. In the tests, three failure modes: flexural failure, shear failure and flexural-shear failure were exhibited for columns. Based on experimental and analytical results, the failure modes and seismic performance of RC square columns were investigated; deformation capacity and displacement components (flexural displacement, shear displacement and anchorage slip displacement) of columns were also analyzed.

\section{Experimental program}

\subsection{Specimens details}

Existing experimental and analytical results indicate that concrete strength, longitudinal steel ratio, transverse reinforcement ratio, shear aspect ratio and axial load ratio can significantly affect the seismic failure modes, hysteretic characteristics and deformation capacity of columns. For columns with large shear aspect ratio, small axial load ratio and proper transverse reinforcement, column response is dominated by flexure, and flexural failure occurs. Whereas, for columns with small shear aspect ratio, large axial load ratio and poor transverse reinforcement, shear is considered as the dominating failure mechanism. Flexural-shear failure is a failure pattern between flexural failure and shear failure. Considering that it is difficult to determine the experimental parameters for columns exhibiting flexural-shear failure, the shear aspect ratio, axial load ratio and stirrup spacing (transverse reinforcement ratio) of test specimens are taken as control variables in the test.

A total of $24 \mathrm{RC}$ column specimens with square crosssection of $200 \mathrm{~mm} \times 200 \mathrm{~mm}$ under combined reversed cyclic displacement excursions and axial loads were conducted. The geometry of the column specimens and the reinforcement layout are shown in Fig. 1. The column specimens had the same concrete clear cover of $20 \mathrm{~mm}$ and two stub dimensions of $1300 \mathrm{~mm} \times 300 \mathrm{~mm} \times 400 \mathrm{~mm}$ or $500 \mathrm{~mm}$. To investigate the influence of shear aspect ratio, the column heights were 400, $550,700,850,1000$ and $1150 \mathrm{~mm}$ and the corresponding effective shear aspect ratio (ratio of effective column height to effective section height) varied from 1.63 to 6.16 .

All specimens were symmetrically reinforced with two deformed steel bars of diameter $16 \mathrm{~mm}$ in every side of columns as longitudinal bars, providing a reinforcement ratio (total area of longitudinal reinforcement divided by gross section area) of $2.34 \%$. The column specimens were transversely reinforced with rectangular closed hoops with 135-degree hooks at two ends. The transverse steel bars (smooth steel bar of diameter $6.5 \mathrm{~mm}$ ) were spaced at $50 \mathrm{~mm}$ in 12 specimen columns, $100 \mathrm{~mm}$ in the other 12 specimen columns, with the volume transverse reinforcement ratios (total volume of transverse reinforcement divided by the volume of concrete core) $1.54 \%$ and $0.77 \%$, respectively. For the reinforcing steel bars of $16 \mathrm{~mm}$ and $6.5 \mathrm{~mm}$ diameter used in this test, the measured yield strengths were 365.2 $\mathrm{MPa}$ and 346.9 $\mathrm{MPa}$ and the measured ultimate tensile strengths were 545.6 MPa and 508.3 MPa respectively.

The concrete was obtained from a local ready mix plant and designed for target strength of $40 \mathrm{MPa}$. The concrete was used 42.5R Portland cement and medium sand. The ratio of cement, sand, stone and water was 1:1.72:2.56:0.38. Six $150 \mathrm{~mm} \times 150 \mathrm{~mm}$ $\times 150 \mathrm{~mm}$ cubes and three $150 \mathrm{~mm} \times 150 \mathrm{~mm} \times 300 \mathrm{~mm}$ prisms were cast along with the specimens every batch, the RC column specimens were cast by 2 batches. The 28-day mean cube compressive strength was $54.5 \mathrm{MPa}$ and the standard deviation was $4.5 \mathrm{MPa}$. The mean modulus elasticity of concrete measured by the stress-strain relationship of prisms was $3.66 \times 10^{4} \mathrm{~N} / \mathrm{mm}^{2}$.

Two axial load levels were used in this test. The axial load was applied on the top of column specimens and kept constant at $332 \mathrm{kN}$ or $829 \mathrm{kN}$ (approximately $0.2 f_{c}{ }^{\prime} A_{g}$ or $0.5 f_{c}^{\prime} A_{g}$, where $f_{c}^{\prime}$ is the concrete cylinder compressive strength and $A_{g}$ is the gross cross-sectional area). Details of the test specimens are summarized in Table 1 . In the first column of the table, $\mathrm{R}$ denote specimens tested under cyclic loading, the first, second and third numbers refer to shear aspect ratio, axial load ratio and stirrup spacing respectively. For example, R6.16-0.2-50 indicates the column tested under cyclic loading with shear aspect ratio of 6.16, axial load ratio of 0.2 and stirrup spacing of $50 \mathrm{~mm}$.

\subsection{Test Setup}

All the columns were tested under combined constant axial load and reversed cyclic lateral force in a testing frame, as shown in Fig. 2. A constant axial load was applied first using hydraulic loading equipment to simulate the dead load on the column. The reversed cyclic lateral load was then applied through two one-way hydraulic jacks and measured by two load cells attached to the hydraulic jacks. Readings of forces from load cells were recorded at time intervals of 50 milliseconds throughout the loading. 

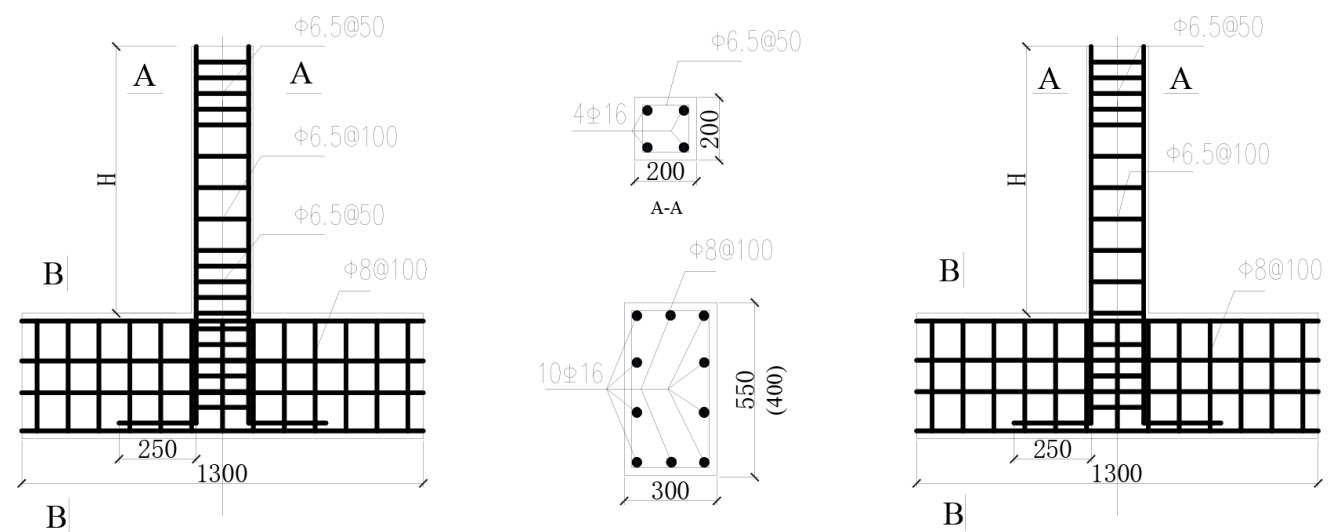

Fig. 1 Dimensions and reinforcement details of column specimens

Table 1 Column test parameters

\begin{tabular}{|c|c|c|c|c|c|c|c|c|c|}
\hline Specimen ID & $\mathrm{H}(\mathrm{mm})$ & $\mathrm{H}_{0}(\mathrm{~mm})^{\mathrm{a}}$ & $\mathrm{B}(\mathrm{mm})$ & $\mathrm{D}(\mathrm{mm})$ & $\lambda^{\mathrm{b}}$ & $\mathrm{N}(\mathrm{kN})$ & $\mathrm{n}^{\mathrm{c}}$ & $\mathrm{S}(\mathrm{mm})^{\mathrm{d}}$ & Failure mode \\
\hline R6.16-0.2-50 & 1150 & 1060 & 200 & 172 & 6.16 & 332 & 0.2 & 50 & Flexure \\
\hline R6.16-0.2-100 & 1150 & 1060 & 200 & 172 & 6.16 & 332 & 0.2 & 100 & Flexure \\
\hline R6.16-0.5-50 & 1150 & 1060 & 200 & 172 & 6.16 & 829 & 0.5 & 50 & Flexural-shear \\
\hline R6.16-0.5-100 & 1150 & 1060 & 200 & 172 & 6.16 & 829 & 0.5 & 100 & Flexural-shear \\
\hline R5.35-0.2-50 & 1000 & 920 & 200 & 172 & 5.35 & 332 & 0.2 & 50 & Flexure \\
\hline R5.35-0.2-100 & 1000 & 920 & 200 & 172 & 5.35 & 332 & 0.2 & 100 & Flexure \\
\hline R5.35-0.5-50 & 1000 & 920 & 200 & 172 & 5.35 & 829 & 0.5 & 50 & Flexural-shear \\
\hline R5.35-0.5-100 & 1000 & 920 & 200 & 172 & 5.35 & 829 & 0.5 & 100 & Flexural-shear \\
\hline R4.33-0.2-50 & 850 & 745 & 200 & 172 & 4.33 & 332 & 0.2 & 50 & Flexure \\
\hline R4.33-0.2-100 & 850 & 745 & 200 & 172 & 4.33 & 332 & 0.2 & 100 & Flexural-shear \\
\hline R4.33-0.5-50 & 850 & 745 & 200 & 172 & 4.33 & 829 & 0.5 & 50 & Flexural-shear \\
\hline R4.33-0.5-100 & 850 & 745 & 200 & 172 & 4.33 & 829 & 0.5 & 100 & Flexural-shear \\
\hline R3.46-0.2-50 & 700 & 595 & 200 & 172 & 3.46 & 332 & 0.2 & 50 & Flexure \\
\hline R3.46-0.2-100 & 700 & 595 & 200 & 172 & 3.46 & 332 & 0.2 & 100 & Flexural-shear \\
\hline R3.46-0.5-50 & 700 & 595 & 200 & 172 & 3.46 & 829 & 0.5 & 50 & Flexural-shear \\
\hline R3.46-0.5-100 & 700 & 595 & 200 & 172 & 3.46 & 829 & 0.5 & 100 & Flexural-shear \\
\hline R2.5-0.2-50 & 550 & 430 & 200 & 172 & 2.5 & 332 & 0.2 & 50 & Flexure \\
\hline R2.5-0.2-100 & 550 & 430 & 200 & 172 & 2.5 & 332 & 0.2 & 100 & Flexural-shear \\
\hline$R 2.5-0.5-50$ & 550 & 430 & 200 & 172 & 2.5 & 829 & 0.5 & 50 & Flexural-shear \\
\hline $\mathrm{R} 2.5-0.5-100$ & 550 & 430 & 200 & 172 & 2.5 & 829 & 0.5 & 100 & Flexural-shear \\
\hline R1.63-0.2-50 & 400 & 280 & 200 & 172 & 1.63 & 332 & 0.2 & 50 & Flexural-shear \\
\hline R1.63-0.2-100 & 400 & 280 & 200 & 172 & 1.63 & 332 & 0.2 & 100 & Flexural-shear \\
\hline R1.63-0.5-50 & 400 & 280 & 200 & 172 & 1.63 & 829 & 0.5 & 50 & shear \\
\hline R1.63-0.5-100 & 400 & 280 & 200 & 172 & 1.63 & 829 & 0.5 & 100 & shear \\
\hline
\end{tabular}

${ }^{a}$ Effective column height, defined as the height from the base to the loading point.

b Shear aspect ratio, defined as the ratio of effective column height to effective column depth $\left(H_{0} / D\right)$.

c Axial load ratio, defined as the ratio of the applied axial load to cylinder strength and gross area of column section ( $\left.N / f_{c}^{\prime} A_{g}\right)$; $N$ is applied axial load, $A_{g}$ is gross cross-sectional area of column, $f_{c}^{\prime}$ is the cylinder compressive strength of concrete specimen (taken as $0.8 f_{c u}$ as suggested by MOHURD (2010)) and $f_{c u}$ is measured concrete compressive strength from cubic specimens.

${ }^{\mathrm{d}} s$ is the spacing measured centre-to-centre of stirrups or hoop sets.

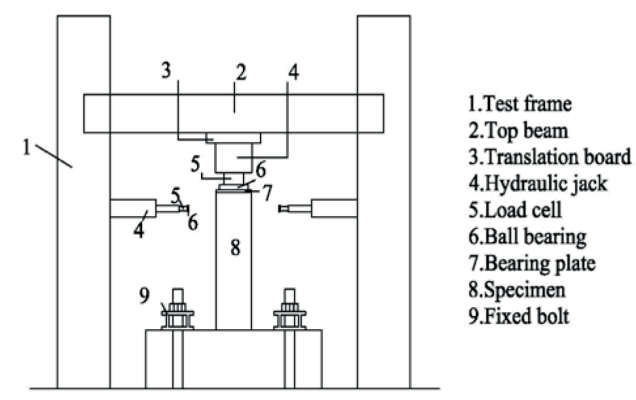

Fig. 2 Details of test setup
To evaluate the contributions of flexural displacement, shear displacement and anchorage slip displacement in total displacement and measure their variations with the change of total displacement, displacement measuring device processed own were mounted in the plastic-hinge of specimens, where approximately $225 \mathrm{~mm}$ above stub, through the use of expansion screws pre-embedded in specimens. As shown in Fig. 3(a) and (c), 1\# and 2\# electronic displacement meters were mounted symmetric longitudinally over a plastic-hinge length of specimen sides 
to monitor the tension and compression of concrete outer edge, which can calculate the average curvature in the plastic-hinge. 3\# electronic displacement meter was mounted horizontally to measure the flexural displacement and shear displacement in the plastic-hinge. 4\# electronic displacement meter was used to measure the total lateral displacement at loading point of the column end, as shown in Fig. 3(a) and (d). All electronic displacement meters held with specially designed fixtures were connected with expansion screws to avoid instrument damage caused by large displacement, as shown in Fig. 3. Electrical resistance strain gauges were arranged on the longitudinal bars and transverse bars above the stub to measure the strains at different loading levels. The arrangement of strain gauges is shown in Fig. 3(b). Readings of displacements and strains from electronic displacement meters and resistance strain gauges were also recorded at time intervals of 50 milliseconds throughout the loading.

Three full cycles were applied at each displacement using a triangular waveform. The initial displacement corresponded to $\Delta 1=2 \mathrm{~mm}$, which was a preloading displacement. Subsequent displacements were increased to $2 \Delta 1 ; 4 \Delta 1 ; 6 \Delta 1 \ldots$, etc, until the column failed (Fig. 4). Failure was declared if the peak load during a given set of three cycles dropped to $85 \%$ the absolute maximum load attained during the previous set, or if the third load dropped to $85 \%$ the maximum load during a given displacement of three cycles, or if a serious damage occurs and the column specimen is unable to bear axial load.

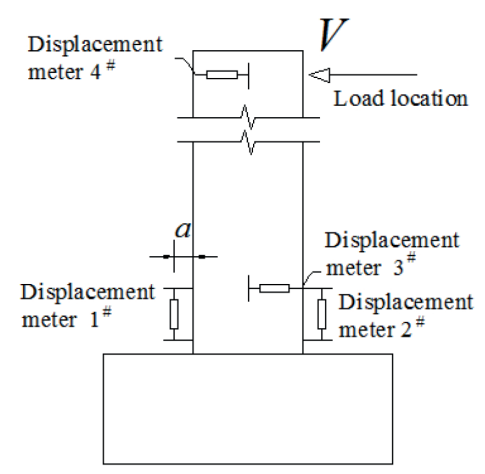

(a)

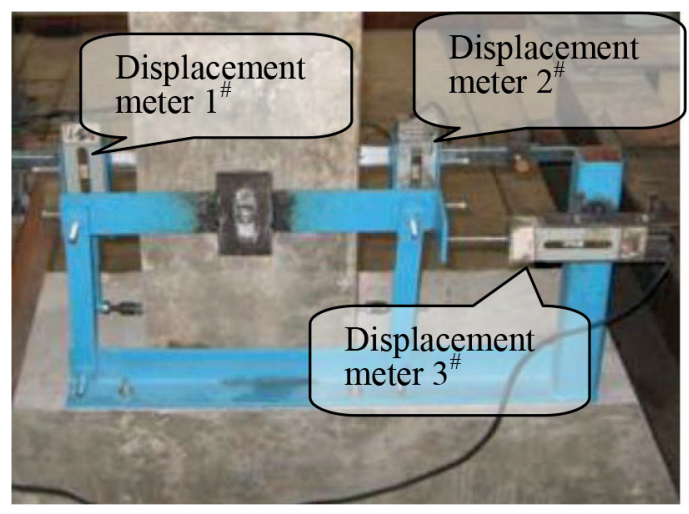

(c)

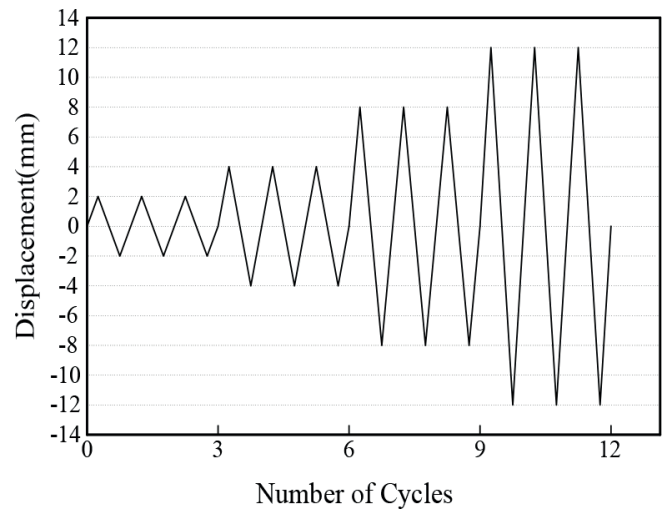

Fig. 4 Horizontal displacement history

\section{Experimental results}

\subsection{Failure models}

$\mathrm{RC}$ columns subjected to low cyclic lateral loads exhibit three failure modes (flexural failure, shear failure and flexuralshear failure) in test, as summarized in Table 1. The appearance of some of the damaged column specimens is shown in Fig. 5.

\subsubsection{Flexural failure}

The flexural failure mode, which mainly occurs in the columns with large aspect ratio and low axial load ratio, is dominated by flexural capacity. The first crack occurred perpendicular to the column axis about $100 \mathrm{~mm}$ from the stub interface. With increasing lateral load, the number of horizontal cracks increased and continued to develop. During cycles beyond the yielding of longitudinal reinforcement, several diagonal cracks

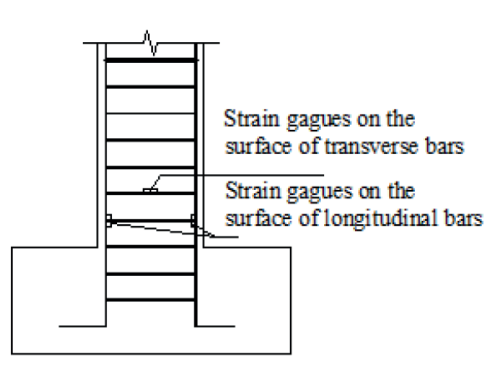

(b)

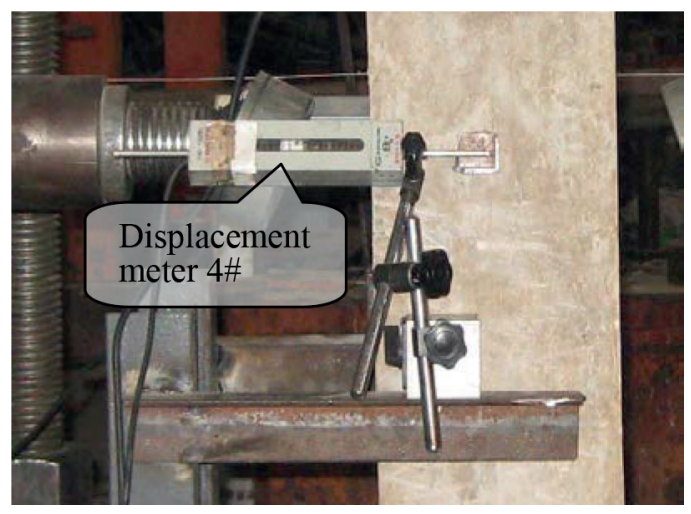

(d)

Fig. 3 Layout of instrument 
appeared. These cracks were distributed within $300 \mathrm{~mm}$ from the stub interface. Finally, the concrete reached the ultimate compression strain, concrete crushing was observed, but the stirrup did not yield. Fig. 5(a) displays the failure pattern of specimen R5.35-0.2-50 failed in flexure.

\subsubsection{Shear failure}

The shear failure mode, which mainly occurs in the columns with small aspect ratio and high axial load ratio, is dominated by shear capacity. The several hairline cracks first appeared at the bottom of the specimens. When horizontal load increased to approximately $75 \%$ of the maximum load, the first diagonal crack occurred. As the lateral load continued to increase, new inclined cracks appeared and widened in the region from the bottom end of specimen to the loading point. Once the lateral load was at maximum load, sudden brittle failure occurred with a deep diagonal crack and concrete crushing near the base stub, as shown in Fig. 5(b). For this failure mode, the longitudinal bars did not yield and failure was initiated by the penetration of shear cracks through the core concrete accompanied by yielding of the transverse reinforcement.

\subsubsection{Flexural- shear failure}

Flexural -shear failure, which mainly occurs in the columns with medium aspect ratio and high axial load ratio, or insufficient stirrup layout, is another failure mode in-between flexure and shear modes. The horizontal flexural cracks perpendicular to column axis formed firstly. As the lateral load increased, the flexural cracks became inclined, and new inclined cracks appeared due to shear. After yielding of longitudinal reinforcement, cross-diagonal cracks and several vertical cracks along the longitudinal reinforcement were noted and spalling of cover concrete at the column end was observed, suggesting that the shear strength contribution from the concrete reduces. As displacement was increased, transverse reinforcement yielding and was followed by some buckling of longitudinal bars and crushing of core concrete in the subsequent. The failure pattern of R4.33-0.2-100 and R3.46-0.5-100, which failed in flexuralshear, are shown in Figs. 5(c) and 5(d).

To avoid the brittle shear failure and ensure flexural-shear failure of columns with sufficient deformation, the optimum design parameters of RC columns are: shear aspect ratio $2 \leq \lambda \leq$ 6 , axial load ratio $n \leq 0.2$, and volume transverse reinforcement ratios $1 \% \leq \rho_{v} \leq 3 \%$.

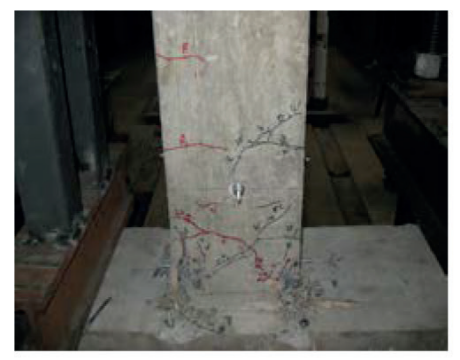

(a) Flexural failure R5.35-0.2-50

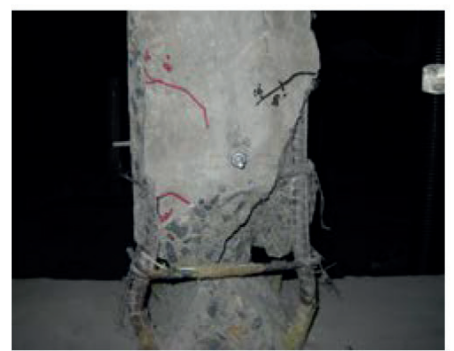

(c) Flexural-shear R4.33-0.2-100

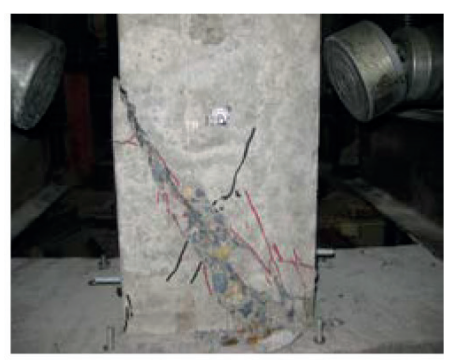

(b) Shear failure R1.63-0.5-100

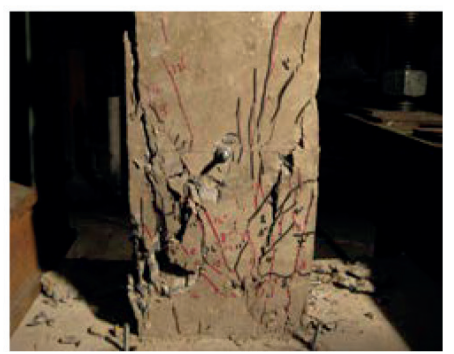

(d) Flexural-shear R3.46-0.5-100
Fig. 5 Failure of column specimens

\subsection{Hysteretic Responses}

Lateral load-lateral displacement hysteretic curves for column specimens with three typical failure modes are shown in Fig. 6. In the figures, the shear-failure points of specimens are marked as “๑”. In general, specimens failed in flexure exhibited well ductile performance with plump hysteretic loops and larger ultimate displacement. No significant strength deterioration and stiffness degradation occurred and no pinching can be observed, as shown in Figs. 6 (a). However, specimens failed in shear show less ductile performance with thin hysteretic loops and smaller ultimate displacement. A sudden strength reduction after the peak lateral forces and obvious pinching effect are observed in the hysteretic loops, as shown in Figs. 6 (b). Specimens failed in flexural-shear were able to maintain stable responses with full hysteretic loops until displacement levels $2 \Delta_{\mathrm{y}} \sim 4 \Delta_{\mathrm{y}}$. Thereafter, the hysteretic loops showed pinching effect and the specimens lost the lateral load-carrying capacities suddenly. The phenomenon suggests that the inelastic response of column specimens was initially controlled by flexure but was ultimately dominated by shear. The specimens showed limited ductile behaviour and failed in shear failure finally after flexural yielding, as shown in Figs. 6 (c). 


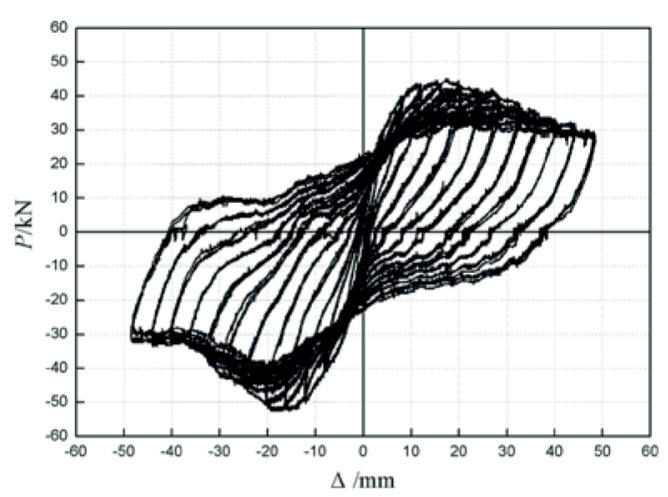

(a) Flexural failure R6.16-0.2-50

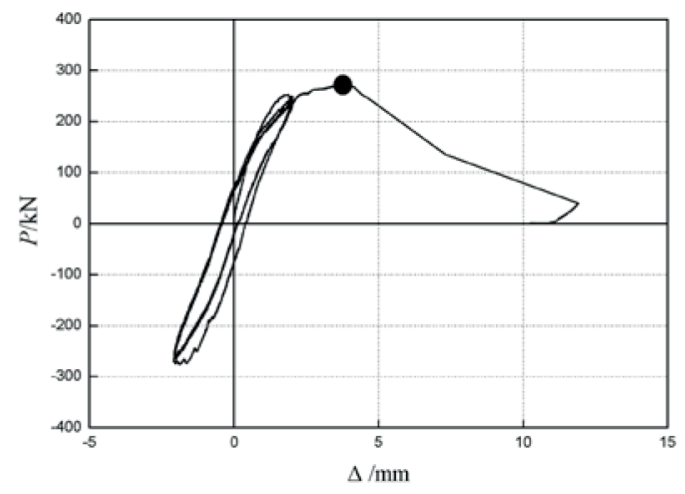

(b) Shear failure R1.63-0.5-100

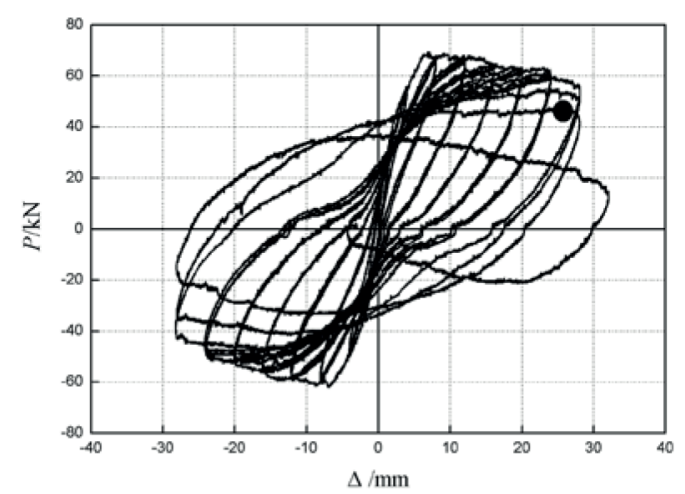

(c) Flexural-shear failure R4.33-0.2-100

Fig. 6 Force-displacement hysteretic responses for specimens

\subsection{Deformation capacity}

In seismic design and researches, the inelastic deformation of structures or elements has been always focused on, because the inelastic deformation could absorb and dissipate seismic energy to reduce earthquake response. The inelastic deformation is generally quantified by ductility, which means deformation capacity in the case without apparent strength and stiffness degradations after yielding of longitudinal reinforcement.

Displacement ductility of a structure or member is usually measured by displacement ductility factor, $\mu_{\Delta}=\left(\left(\left|\Delta_{+u}\right|+\left|\Delta_{-u}\right|\right) /\right.$ $\left.\left(\left|\Delta_{+y}\right|+\left|\Delta_{-y}\right|\right)\right)$, in which $\Delta_{u}$ is the ultimate displacement, i.e. the displacement corresponding to $85 \%$ of the maximum load usually; and $\Delta_{y}$ is the yield displacement. The values of $\mu_{\Delta}$ calculated with this method are approximately the same for specimens failed in flexural-shear and flexure; even in the case with small shear aspect ratio, $\mu_{\Delta}$ for specimens failed in flexural-shear are even slightly larger than that of specimens failed in flexure, which are obviously inconsistent with engineering practice. This is considered due to the facts that (1) $\Delta_{y}$ increase approximately with of the quadratic increase of specimen length, while $\Delta_{u}$ increases linearly; (2) specimens failed in flexural-shear often develop relatively stable flexural responses up to the level of $2 \Delta_{y} \sim 4 \Delta_{y}$, and then fail in shear suddenly. So, $\Delta_{u}$ for specimens failed in flexural-shear and flexure, using above method, can not reasonably reflect the variation of deformation capacity after longitudinal reinforcement yielding. To reflect the displacement changes from yielding of longitudinal reinforcement until failure, the relationship of $\Delta / \Delta_{y}$ ( the ratio of displacement at any moment after yielding, i.e. from yielding until failure, to yield displacement) and $P / P_{\mathrm{y}}$ ( the ratio of horizontal load at any moment after yielding to yield load) are plotted in Fig. 7.

As shown in Figs.7 (a) and (b), for specimens failed in flexure(such as R6.16-0.2-50, R5.35-0.2-50, R4.33-0.2-50, R6.16-0.2-100, R5.35-0.2-100), $\Delta / \Delta_{\mathrm{y}}$ almost presents a horizontal line growth after $P / P_{\mathrm{y}}$ declining to 0.7 . It is illustrated that the deformation capacity of column failed in flexure presents a continuous increase after longitudinal reinforcement yielding. For specimens failed in shear (for example R1.630.5-50, R1.63-0.5-100), are known as brittle failure, the lateral load-carrying capacity declines sharply after the maximum load, and little or no measurable plastic deformation is developed, as shown in Fig.7 (f). Specimens failed in flexural-shear (for instance R6.16-0.5-50, R1.63-0.2-50, etc) and flexure have the similar deformation capacity when $P / P_{\mathrm{y}}>0.8$; but the lateral load-carrying capacity decline suddenly and the displacement almost no longer increases when $P / P_{\mathrm{y}}<8.0$, which indicates specimens failed in flexural-shear behave certain deformation capacity between that of specimens failed in flexure and shear.

It should also be noted that the deformation capacity of specimens reduces with the decrease of shear aspect ratio. After yielding of longitudinal reinforcement, long columns develop larger displacement and experience ductile failure, while short columns develop smaller displacement and fail in brittle manners, as shown in Figs. 7 (a)-(d). As shown in Figs. 7(e) and (f), higher axial load may lead to reduction of deformation capacity. For specimens with higher shear aspect ratios, an increase in stirrup spacing does not significantly reduce the deformation capacity of specimens, as shown in Fig. 7(e); but with the decrease of shear aspect ratio, the influence of stirrup spacing on deformation capacity is more obvious, especially for the extreme short columns with shear aspect ratio of 1.63, as shown in Fig. 7(f). 


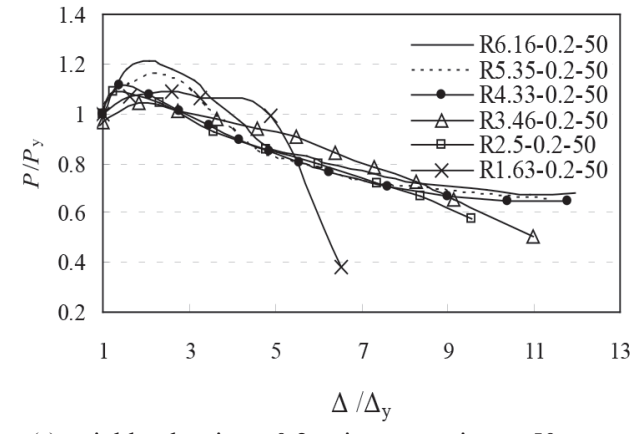

(a) axial load ratio $\mathrm{n}=0.2$, stirrup spacing $\mathrm{s}=50 \mathrm{~mm}$

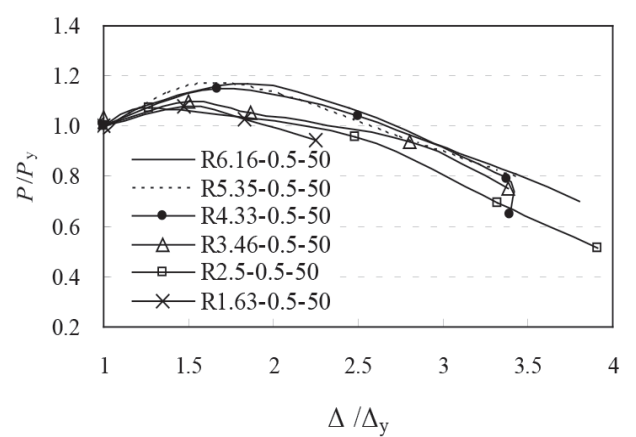

(c) axial load ratio $\mathrm{n}=0.5$, stirrup spacing $\mathrm{s}=50 \mathrm{~mm}$

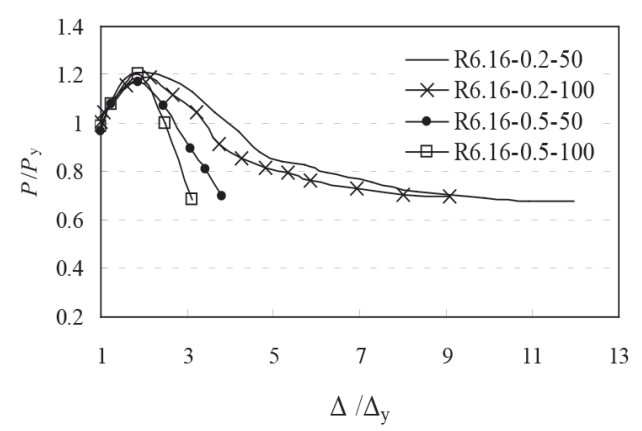

(e) shear aspect ratio $\lambda=6.16$

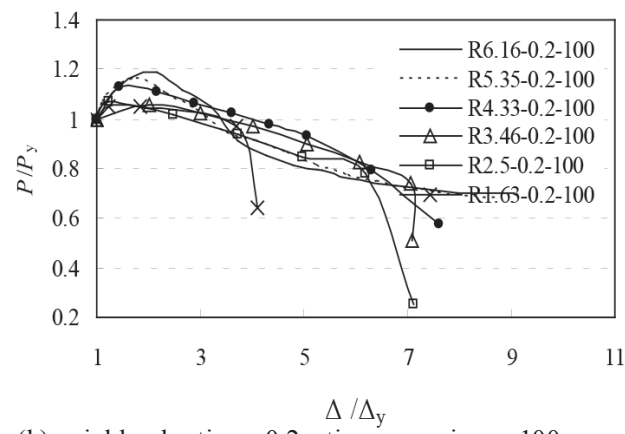

(b) axial load ratio $\mathrm{n}=0.2$, stirrup spacing $\mathrm{s}=100 \mathrm{~mm}$

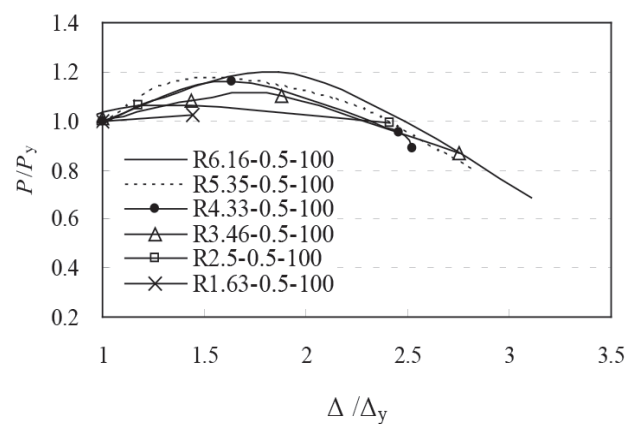

(d) axial load ratio $\mathrm{n}=0.5$, stirrup spacing $\mathrm{s}=100 \mathrm{~mm}$

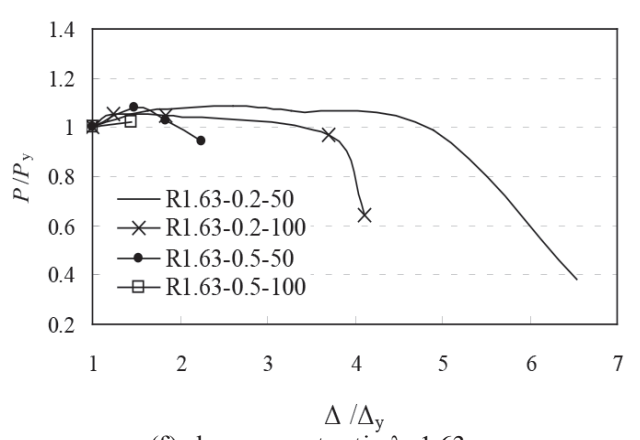

(f) shear aspect ratio $\lambda=1.63$

Fig. 7 Deformability curves of specimens

\section{Discussion of deformation capacity}

The total lateral deformation of column is comprised of three parts: flexural deformation, shear deformation, and deformation due to reinforcement slip at the column end. The contributions of three components to total lateral deformation are different in structures with different structural geometries, internal force conditions and loading procedures. In the analysis of long columns behaviour, it is common to consider the flexural deformation only. However, Experiment results indicate that for short and extreme short columns, shear deformation account for as much as 40 percent of total column deformation, and even exceed the contribution of flexural deformation. Also, Sezen (2002) [12] tested full-scale column specimens in double bending and suggested shear deformation is not ignored. In some cases, the contribution of deformation due to reinforcement slip is so large that it must been considered to ensure the accuracy of analysis results [17]. Ignoring the shear deformation and slip deformation in structural elastic-plastic analysis may overestimate the deformation capacity of structures, and cause a misjudgment of structural stability. Thus, detailed studies on the three deformation components in RC columns are necessary.

\subsection{Displacement analysis}

The lateral displacement represents the deformation capacity of RC columns subjected to lateral cyclic loads. It is mainly caused by the plastic deformation within the plastic-hinge (plastic flexural and shear displacement), the elastic deformation out of plastic hinge region (elastic flexural and shear displacement), and slip of the reinforcing bar in the anchoring concrete. Thus, the traditional practice has been to divide the lateral displacement of columns into three parts: flexural displacement, shear displacement, and reinforcement slip displacement, which are depicted schematically in Fig.8.

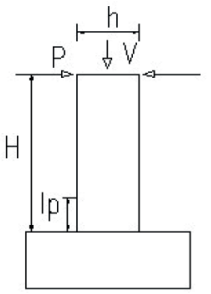

(a)

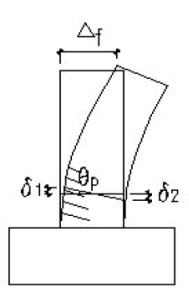

(b)

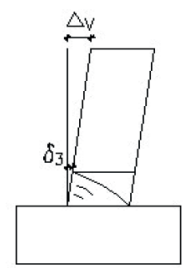

(c)

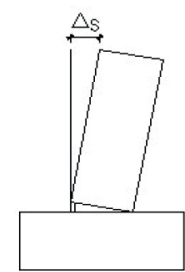

(d)
Fig. 8 Decomposition of horizontal displacement 


\subsubsection{Flexural displacement}

As illustrated in Fig. 8 (b), if the tension, $\delta_{1}$, and compression, $\delta_{2}$, of concrete outer edge in the plastic-hinge are measured, the average section curvature, $\varphi$, in the plastic-hinge can be estimated as

$$
\varphi=\frac{\delta_{1}+\delta_{2}}{l_{\mathrm{p}}(h+2 a)}
$$

where $\delta_{1}$ and $\delta_{2}$ are the displacements at the tension and compression sides of column specimens in the plastic-hinge, which are measured with $1 \#$ and $2 \#$ electronic displacement meters mounted symmetric longitudinally over a plastic-hinge length of specimens sides, as shown in Fig. 3(a) and (c); $h$ is the depth of rectangular cross-section; $l_{p}$ is the equivalent plastichinge length, and can be obtained form $l_{p}=0.08 H+0.022 f_{\mathrm{y}} d_{\mathrm{b}} \geq$ $0.044 f_{\mathrm{y}} d_{\mathrm{b}}[18]$; and $a$ is the horizontal distance between $1 \#$ (or 2\#) electronic displacement meter and column side, and the both distance is the same (shown in Fig. 3 (a)).

Based on the moment-curvature relationship of RC column section and the curvature in the plastic-hinge in Eq.(1), the flexural displacement of cantilever column can be approximately calculated by plastic-hinge model.

$$
\Delta_{\mathrm{f}}=\left\{\begin{array}{cc}
\varphi \frac{H^{2}}{3} & \varphi \leq \varphi_{\mathrm{y}} \\
\varphi_{\mathrm{y}} \frac{H^{2}}{3}+\left(\varphi-\varphi_{\mathrm{y}}\right) l_{\mathrm{p}}\left(H-0.5 l_{\mathrm{p}}\right) & \varphi>\varphi_{\mathrm{y}}
\end{array}\right.
$$

where $\varphi$ is the average curvature in the plastic-hinge region; $\varphi_{\mathrm{y}}$ is the yield curvature; and $H$ is the height of column.

\subsubsection{Shear displacement}

Before the plastic-hinge appears, the shear displacement of columns is mainly elastic shear displacement along the column length; after the plastic-hinge appears, the shear displacement is decomposed into two parts: the inelastic component, $\Delta_{\mathrm{vp}}$, in the plastic-hinge, and the elastic component, $\Delta_{\mathrm{ve}}$, out of the plastic-hinge. As shown in Fig. 8 (c), the shear displacement in the plastic-hinge, $\Delta_{\mathrm{vp}}$, can be obtained by subtracting flexural displacement, $\Delta_{\mathrm{fp}}$, of the plastic-hinge from the lateral displacement (including flexural displacement and shear displacement in the plastic-hinge) measured with $3 \#$ electronic displacement meter.

$$
\begin{gathered}
\Delta_{\mathrm{fp}}=\frac{\delta_{1}+\delta_{2}}{(h+2 a)} l_{\mathrm{p}} \\
\Delta_{\mathrm{vp}}=\delta_{3}-\Delta_{\mathrm{fp}}=\delta_{3}-\frac{\delta_{1}+\delta_{2}}{(h+2 a)} l_{\mathrm{p}}
\end{gathered}
$$

The elastic shear displacement, $\Delta_{\mathrm{ve}}$, out of plastic hinge is given by elastic theory.

$$
\Delta_{\mathrm{ve}}=k \int_{0}^{H-l_{\mathrm{p}}} \frac{V \cdot V_{p}}{G A} d x=1.2 \frac{V\left(H-l_{\mathrm{p}}\right)}{G A}
$$

where $G$ is the shear modulus of concrete; $A$ is the crosssectional area of column, and $G A$ is the shear stiffness of cross-section. $V$ is the horizontal shear load.
The total shear displacement $\Delta_{\mathrm{v}}$ can be obtained by adding the shear displacement in the plastic-hinge, $\Delta_{\mathrm{vp}}$, together with the shear displacement, $\Delta_{\mathrm{ve}}$, out of plastic hinge, and expressed as

$$
\Delta_{\mathrm{v}}=\Delta_{\mathrm{vp}}+\Delta_{\mathrm{ve}}=\delta_{3}-\frac{\delta_{1}+\delta_{2}}{(h+2 a)} l_{\mathrm{p}}+1.2 \frac{V\left(H-l_{\mathrm{p}}\right)}{G A}
$$

The shear displacement in Eq.(6) is still applied to the case before plastic-hinge appearing.

\subsubsection{Slip displacement}

As illustrated in Fig. 8 (d), the slip displacement, $\Delta_{\mathrm{s}}$, can be computed by subtracting shear displacement, $\Delta_{v}$, and flexural displacement, $\Delta_{\mathrm{f}}$, from the total displacement, , as following

$$
\Delta_{\mathrm{s}}=\delta_{4}-\Delta_{\mathrm{f}}-\Delta_{\mathrm{v}}
$$

where $\delta_{4}$ measured with $4 \#$ electronic displacement meter is the total horizontal displacement on loading point of column specimens.

The formula proposed by Sezen (2002) [12] as well as Sezen and Setzler (2008) [17] to calculate the slip displacement, $\Delta_{\mathrm{s}}$, takes the form

$$
\Delta_{\mathrm{s}}=\left\{\begin{array}{cc}
\frac{\varepsilon_{s x} f_{s} d_{b}}{8 u_{b}\left(h_{0}-x_{n}\right)} H & \varepsilon_{s x} \leq \varepsilon_{y} \\
\frac{d_{b}}{8 u_{b}\left(h_{0}-x_{n}\right)}\left[\varepsilon_{y} f_{y}+2\left(\varepsilon_{s x}+\varepsilon_{y}\right)\left(f_{s}-f_{y}\right)\right] H & \varepsilon_{s x}>\varepsilon_{y}
\end{array}\right.
$$

where $\varepsilon_{s x}$ is the strain of reinforcing bar at the interface of column and stub; $f_{s}$ is the stress of reinforcing bar corresponding to $\varepsilon_{s x} ; \varepsilon_{y}$ is the steel yield strain; $d_{b}$ is the diameter of reinforcing bar; $h_{0}$ and $x_{n}$ are the distances from the extreme compression fiber to the center of tension steel and to the neutral axis, respectively; and $u_{b}$ is the bond stresses over the extending length of reinforcing bar, equal to $1.0 \sqrt{f_{c}^{\prime}}$ before yielding, and $0.5 \sqrt{f_{c}^{\prime}}$ after yielding.

The slip displacements calculated by Eq.(8) agree well with the indirect test measured data, provide by Eq.(7), as shown in Fig.9. Note that for the column specimens with different stirrup spacing, the slip displacement calculation values are the same because Eq.(8) has not consider the influence of stirrup spacing.

\subsection{Displacement components}

Based on the values of $\delta_{1}, \delta_{2}, \delta_{3}$ and $\delta_{4}$ measured in tests, the variations of displacement component contributions with the increase of total displacement are estimated, as shown in Fig. 10.

\subsubsection{Flexural displacement}

Flexural displacement increases with the increase of total displacement, but the contribution of flexural displacement in total displacement, calculated as average value of $\Delta_{\mathrm{f}} / \Delta$ at different displacement, decreases. For specimens with the same axial load ratio and stirrup spacing, the decrease of shear aspect 

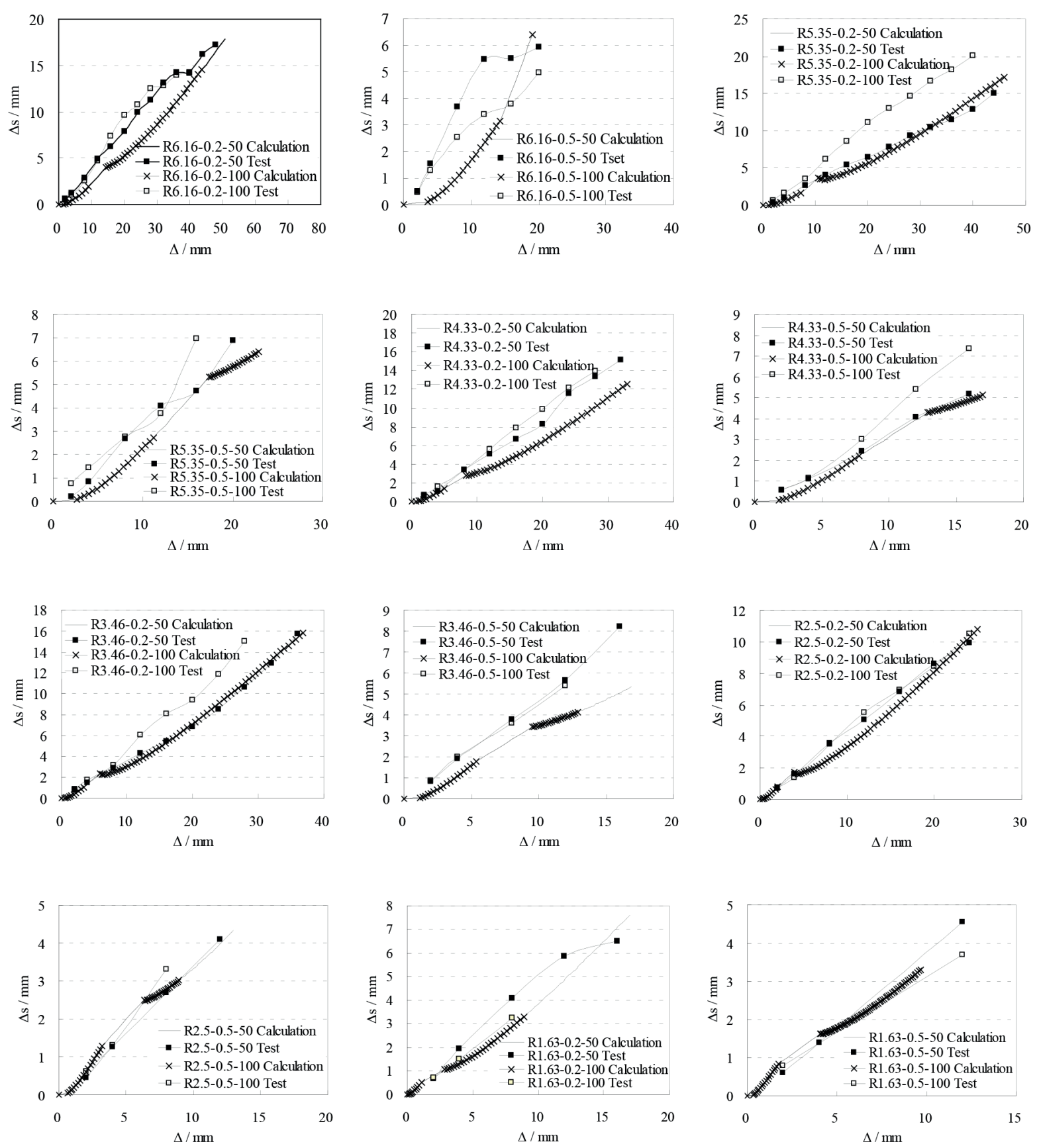

Fig. 9 Comparisons between calculated and experimental results of slip displacement

ratio results in a degradation of flexural displacement contribution $\left(\Delta_{\mathrm{f}} / \Delta\right)$, and the magnitude of decrease tends to be larger as the shear aspect ratio decreases. For specimens with axial load ratio of 0.2 and stirrup spacing of $100 \mathrm{~mm}$, the $\Delta_{\mathrm{f}} / \Delta$ values of specimens R5.35-0.2-100, R4.33-0.2-100, R3.46-0.2100, R2.5-0.2-100 and R1.63-0.2-100 were reduced by $20.3 \%$, $22.92 \%, 32.83 \%, 45.77 \%$ and $74.36 \%$, respectively, comparing with that of specimen R6.16-0.2-100.

For specimens with different axial load ratios only, $\Delta_{\mathrm{f}} / \Delta$ increases as the axial load ratio increases, and the increase magnitude tends to be larger with the increase of the total displacement, as shown in Figs. 10 (b) and (c). For example, the value of $\Delta_{\mathrm{f}} / \Delta$ for specimen R6.16-0.5-100 with axial load ratio of 0.5 is increased by $4.27 \%$ at a total displacement of $2 \mathrm{~mm}$, $59.67 \%$ at $20 \mathrm{~mm}$, comparing with the specimen R6.16-0.2-100 with axial load ratio of 0.2 . This is considered due to the fact that the increase of axial compression ratio accelerates concrete buckling, which lead to increased average compressive strain and flexural deformation.

For specimens with different stirrup spacing, $\Delta_{\mathrm{f}} / \Delta$ decreases with the increase of stirrup spacing, as shown in Figs.10 (a) and (b). When stirrup spacing increase $50 \mathrm{~mm}$ to $100 \mathrm{~mm}$, comparing specimen R6.16-0.2-100 with R6.16-0.2-50, R5.35-0.2-100 with R5.35-0.2-50, R4.33-0.2-100 with R4.33-0.2-50, R3.460.2-100 with R3.46-0.2-50, R2.5-0.2-100 with R2.5-0.2-50, R1.63-0.2-100 with R1.63-0.2-50, the values of $\Delta_{\mathrm{f}} / \Delta$ are reduced by $2.62 \%, 31.46 \%, 17.36 \%, 28.49 \%, 17.4 \%, 22.74 \%$. 


\subsubsection{Shear displacement}

With the increase of total displacement, shear displacement also increases. The increase rate is slow before stirrup yielding and the contribution, average value of $\Delta_{v} / \Delta$ at different displacement, is $10 \% \sim 20 \%$. Once the stirrup yield, shear displacement suddenly increase and $\Delta_{\mathrm{v}} / \Delta$ is about $15 \%$, even exceed $30 \%$.

For specimens with different shear span ratios only, shear displacement increases with the decrease of shear aspect ratio. The contribution of shear displacement in total displacement, $\Delta_{\mathrm{v}} / \Delta$, also has the same trend, and the increase magnitude tends to be larger with the decrease of shear aspect ratio, as shown in Figs.10 (b) and (d). For specimens with axial load ratio of 0.2 and stirrup spacing of $100 \mathrm{~mm}$, the $\Delta_{v} / \Delta$ values of specimens R5.35-0.2-100, R4.33-0.2-100, R3.46-0.2-100, R2.5-0.2-100 and R1.63-0.2-100 were increased by 0.19, 1.53, $1.59,2.12$ and 2.10 times, respectively, comparing with that of specimen R6.16-0.2-100. For specimens had the same axial load ratio of 0.2 and stirrup spacing of $50 \mathrm{~mm}, \Delta_{\mathrm{v}} / \Delta$ is $21.51 \%$ for specimen R1.63-0.2-50 with shear aspect ratio of 1.63 , while is $11.81 \%$ for specimen R6.16-0.2-50 with that of 6.16 at the time of specimen failing.

The contribution of shear displacement in total displacement, $\Delta_{v} / \Delta$, increases as stirrup spacing increases, and the increase magnitude tends to be larger with the decrease of shear aspect ratio. For specimens with axial load ratio of 0.2 , stirrup spacing increase $50 \mathrm{~mm}$ to $100 \mathrm{~mm}$, comparing specimen R6.16-0.2-100 with R6.16-0.2-50, R5.35-0.2-100 with R5.35-0.2-50, R4.330.2-100 with R4.33-0.2-50, R3.46-0.2-100 with R3.46-0.2-50, R2.5-0.2-100 with R2.5-0.2-50, and R1.63-0.2-100 with R1.63$0.2-50$, the values of $\Delta_{v} / \Delta$ are increased by $4.67 \%, 23.72 \%$, $29.68 \%, 30.59 \%, 42.59 \%$ and $100.02 \%$, respectively.

If the shear aspect ratio and stirrup spacing of specimens are the same, the contribution of shear displacement, $\Delta_{\mathrm{v}} / \Delta$, is not notably influenced by axial load ratio for specimens with $\lambda>3$; but for specimens with $\lambda<3$, the value of $\Delta_{\mathrm{v}} / \Delta$ increases with the increase of axial load ratio. For short column specimen with shear aspect ratio of 1.63 and stirrup spacing of $100 \mathrm{~mm}$, comparing specimen R1.63-0.5-100 with R1.63-0.2-100, axial load ratio increase from 0.2 to 0.5 , the values of $\Delta_{\mathrm{v}} / \Delta$ are increased by $60.79 \%$; while for long column specimen, the values of have little change. Specimen R1.63-0.5-100 had higher axial load ratio of 0.5 , smaller shear aspect ratio of 1.63 and larger stirrup spacing of $100 \mathrm{~mm}$, experienced a brittle shear failure with $\Delta_{\mathrm{v}} / \Delta$ up to $51.05 \%$, as shown in Fig. 10 (e).

\subsubsection{Slip displacement}

Slip displacement also increases with the increase of total displacement. The contribution of slip displacement in total displacement, calculated as average value of $\Delta_{\mathrm{s}} / \Delta$ at different displacement, tends to increase slightly at the range of $\Delta_{\mathrm{y}} \sim 3 \Delta_{\mathrm{y}}$, while remains unchanged after $3 \Delta_{y}$. The average values of $\Delta_{\mathrm{s}} / \Delta$ for all specimens are approximately $30 \% \sim 40 \%$.
The variation of each displacement component in three failure modes is evaluated by average value of all test specimens. For specimens failed in flexure, the contributions of flexural displacement, shear displacement and slip displacement in the total displacement are $50 \%, 11 \%$ and $39 \%$, respectively. In total displacement, the flexural displacement is dominant and the shear displacement contribution is relatively less. The contributions of flexural displacement, shear displacement and slip displacement are $38 \%, 28 \%$ and $34 \%$ for specimens failed in shear, and $49 \%, 14 \%$ and $38 \%$ for specimens failed in flexural-shear, respectively. The shear displacement contribution increases with loading, especially the coming shear failure. Therefore, to get an accurate prediction of structural performance, the three deformation compositions must be taken into consideration in the elastic-plastic seismic analysis of RC columns.

\section{Conclusions}

$24 \mathrm{RC}$ square columns with different shear aspect ratios, axial load levels, and transverse reinforcement configurations have been experimentally studied. Based on the analysis of test results, the following conclusions can be made:

(1) RC columns under cyclic loads usually exhibit three failure modes: flexural failure, shear failure and flexural- shear failure. The brittle shear and flexural-shear failure modes, which mainly occurs in the columns with small shear aspect ratio, high axial load ratio, or insufficient reinforcement layout, should be pay attention to. The optimum design parameters of RC columns are: shear aspect ratio $2 \leq \lambda \leq 6$, axial load ratio $\mathrm{n} \leq 0.2$, and volume transverse reinforcement ratios $1 \%$ $\leq \rho_{\mathrm{v}} \leq 3 \%$.

(2) The seismic failure modes influence the energy dissipation capacity and ductility of RC columns. The flexural failure columns exhibit good energy dissipation capacity and ductility. The shear failure columns appear to have poor hysteretic response and no plastic deformation capacity. The flexuralshear failure columns show limited energy dissipation and ductile behaviour, however, are weaker than that of flexural failure ones. Note that RC columns failed in flexural-shear are not easy to identify and there is no uniform analysis model recently, thereby it should be ensure they have well deformation capacity after flexural yielding.

(3) With the increase of total displacement, all of the three deformation components (flexural, shear, and slip deformation) increase, the contribution of flexural displacement in total displacement decreases, the contribution of shear displacement increases, especially the coming shear failure, and the contribution of slip displacement varies slightly in the range $30 \% \sim 40 \%$. To get an accurate prediction of structural displacement, the shear and slip displacement must be taken into consideration in the elastic-plastic seismic analysis of RC columns; otherwise the displacement will be overestimate. 

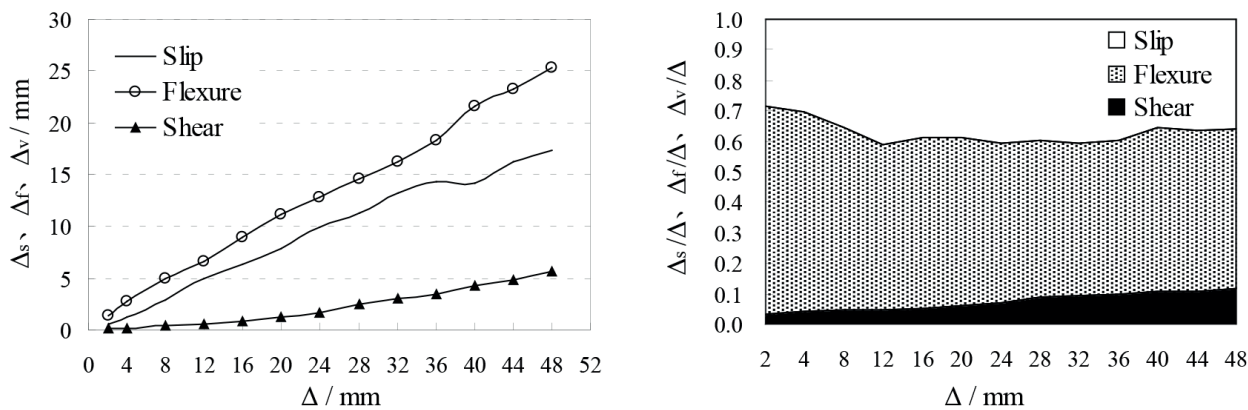

(a) R6.16-0.2-50
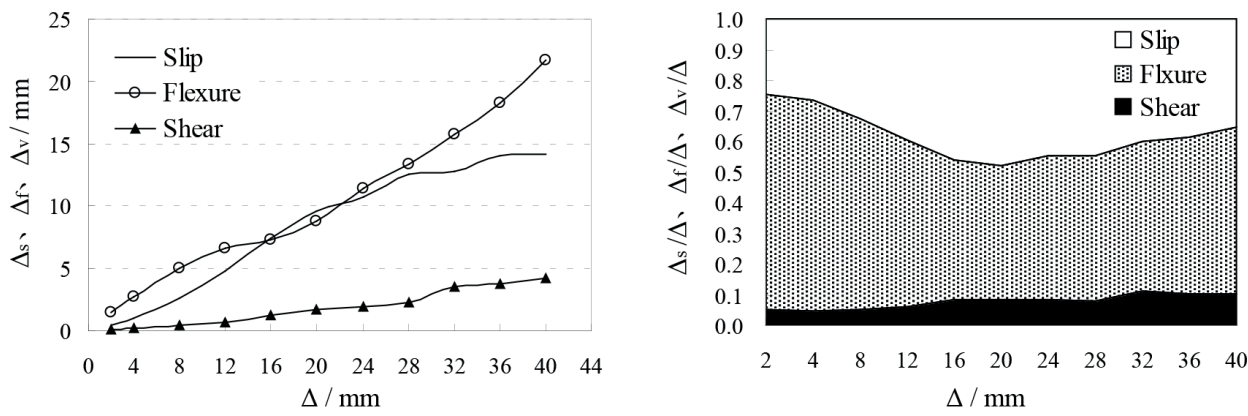

(b) R6.16-0.2-100
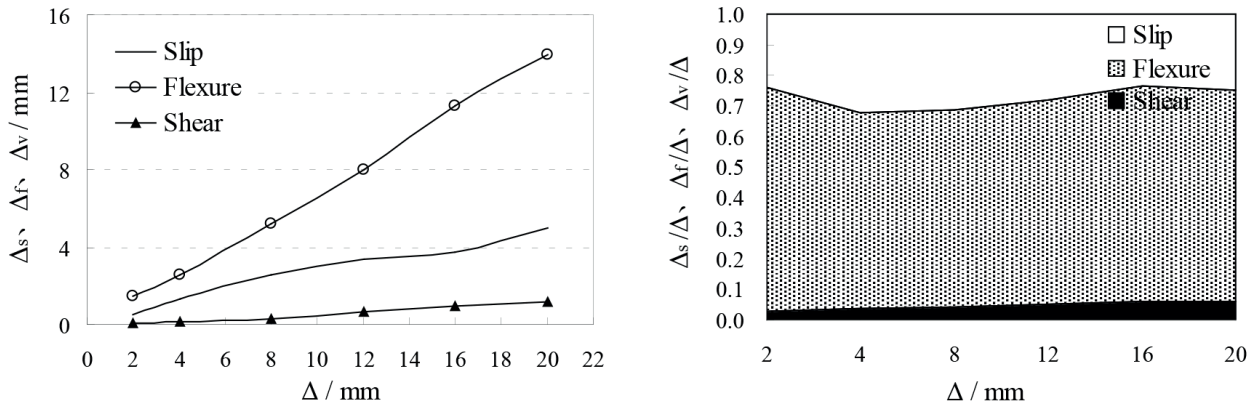

(c) R6.16-0.5-100
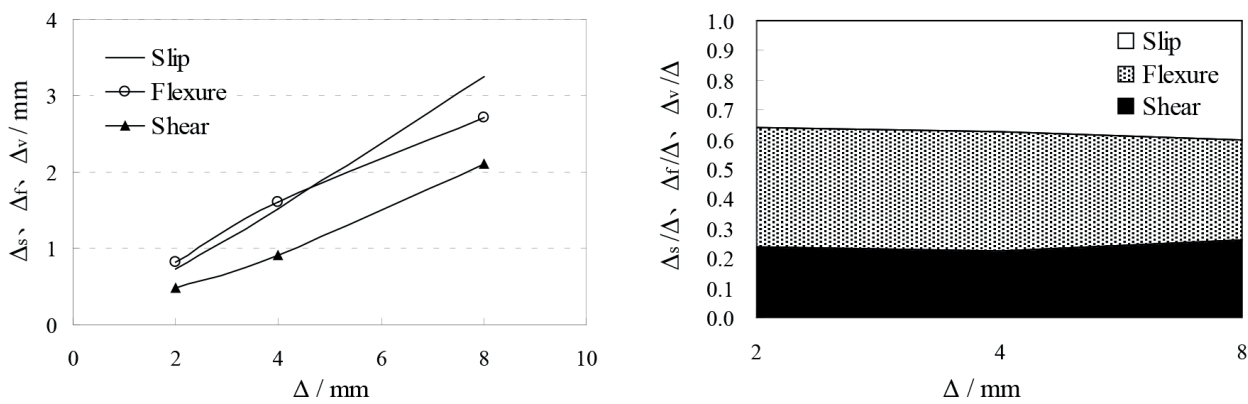

(d) R1.63-0.2-100
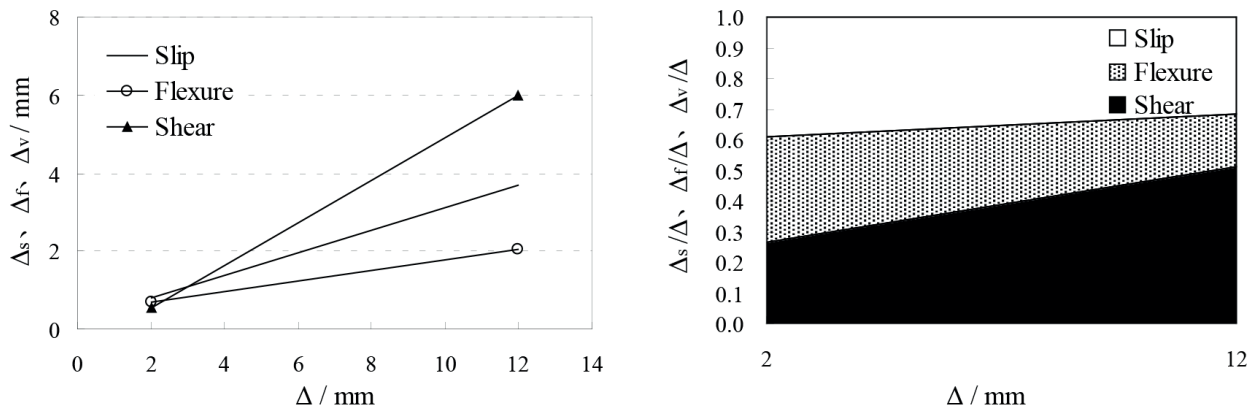

(e) R1.63-0.5-100

Fig. 10 Displacement decomposition history curve 
(4) The influences of longitudinal reinforcement ratio, concrete and reinforcement strength on the failure modes and seismic performance of RC columns are not incorporated in this study, which will be involved in further studies.

\section{Acknowledgement}

The research described in this paper was financed by the National Natural Science Foundation of China (Grant No. 51408223, No. 51278081, No. 51679092, U1404529). The authors wish to express their gratitude for this financial support.

\section{References}

[1] Kawashima, K. "Seismic performance of RC bridge piers in Japan: an evaluation after the 1995 Hyogo-ken nanbu earthquake". Progress in Structural Engineering and Materials, 2(1), pp. 82-1. 2000. https://doi.org/10.1002/(SICI)1528-2716(200001/03)2:1<82::AIDPSE10>3.0.CO;2-C

[2] Hashimoto, S., Fujino, Y., Abe, M. "Damage Analysis of Hanshin Expressway Viaducts during 1995 Kobe Earthquake”. II: Damage Mode of Single Reinforced Concrete Piers, Journal of Bridge Engineering. 10(1), pp. 45-53. 2005. https://doi.org/10.1061/(ASCE)1084-0702(2005) 10:1(45)

[3] Hsu, Y. T., Fu, C. C. "Seismic effect on highway bridges in Chi Chi earthquake". Journal of performance of constructed facilities, 18(1), pp. 47-53. 2004. https://doi.org/10.1061/(ASCE)0887-3828(2004)18:1(47)

[4] Wang, D., Guo, X., Sun, Z. G., Meng, Q. L., Yu, D. H., Li, X. L. “Damage to Highway Bridges During Wenchuan Earthquake". Journal of Earthquake Engineering and Engineering Vibration, 29(3), pp. 84-94. 2009.

[5] Setzler, E. J., Sezen, H. "Model for the lateral behavior of reinforced concrete columns including shear deformations". Earthquake Spectra, 24(2), pp. 493-511. 2008. https://doi.org/10.1193/1.2932078

[6] Priestley, M J N., Verma, R., Xiao, Y. "Seismic shear strength of reinforced concrete columns". Journal of Structural Engineering, 120(8), pp. 23102329. 1994. https://doi.org/10.1061/(ASCE)0733-9445(1994)120:8(2310)

[7] Lehman, D., Moehle, J., Mahin, S., Calderone, A., Henry, L. "Experimental evaluation of the seismic performance of reinforced concrete bridge columns". Journal of Structural Engineering, 130(6), pp. 869-879. 2004. https://doi.org/10.1061/(ASCE)0733-9445(2004) 130:6(869)

[8] Xiao, J., Zhang, C. "Seismic behavior of RC columns with circular, square and diamond sections". Construction and Building Materials, 22(5), pp. 801-810. 2008. https://doi.org/10.1016/j.conbuildmat.2007.01.010

[9] Si, B. J., Li, H. N., Wang, D. S., Sun, Z. G., Wang, Q. X. "Experimental Evaluation of the Seismic Performance of Reinforced Concrete Bridge Piers Designed on the Basis of Displacement (I) : Quasi-static Test”. Journal of Earthquake Engineering and Engineering Vibration, 28(1), (2008), pp. 123-129. 2008. https://doi.org/10.13197/j.eeev.2008.01.008

[10] Lynn, A. C., Moehle, J. P., Mahin, S. A.,.Holmes, W. T. "Seismic evaluation of existing reinforced concrete building columns". Earthquake Spectra, 12(4), pp. 715-739. 1996. https://doi.org/10.1193/1.1585907

[11] Xiao, Y., Martirossyan, A. "Seismic performance of high-strength concrete columns". Journal of Structural Engineering, 124(3), pp. 241251. 1198. https://doi.org/10.1061/(ASCE)0733-9445(1998)124:3(241)

[12] Sezen, H. "Seismic behavior and modeling of reinforced concrete building columns". PhD thesis, University of California, Berkeley, 2002.

[13] Si, B. J., Su, Z. G., Du, X. L., Wang, D. S., Huang, Z..N. "Study on the seismic flexural-shear damage mechanisms and rapid repair techniques for earthquake damaged bridge piers". China Civil Engineering Journal, 44(7), pp. 90-99, 2011. https://doi.org/10.15951/j.tmgcxb.2011.07.011
[14] Lehman, D. E., Moehle, J.. P. "Seismic performance of well-confined concrete bridge columns, Report No. PEER-1998/01" Pacific Earthquake Engineering Research Center, University of California, Berkeley, 2000. http://peer.berkeley.edu/publications/peer_reports/ reports_1998/9801.pdf

[15] Li, Y. "A simulation and Test of nonlinear deformation decomposition in reinforced concrete columns". Master thesis, Chongqing University, China, 2010.

[16] Cai, M., Gu, X. L., Hua, J. J., Lin, F. "Seismic response analysis of reinforced concrete columns considering shear effects". Journal of Building Structures, 32(11), pp. 97-108. 2011. https://doi.org/10.14006/j. jzjgxb.2011.11.003

[17] Sezen, H., Setzler, E. J. „Reinforcement slip in reinforced concrete columns”. ACI Structural Journal, 105(3), pp. 280-289, 2008.

[18] Priestley, M. J. N., Park, R. "Strength and ductility of concrete bridge columns under seismic loading". ACI Structural Journal, 84(1), pp. 61-76. 1987. 